\title{
Synthesis of Adenosine 3':5'-Cyclic Monophosphate in Salmonella typhimurium Growing in Continuous Culture
}

\author{
By JAMES G. HAR MAN AND J. L. BOTSFORD \\ Department of Biology, New Mexico State University, Las Cruces, \\ New Mexico 88003, U.S.A.
}

(Received 3 July 1978; revised 21 August 1978)

\section{INTRODUCTION}

The activity of adenylate cyclase (EC 4.6.1.1) in Escherichia coli and Salmonella typhimurium is thought to be inhibited when a carbon source is transported into the cell (Saier \& Feucht, 1975; Saier et al., 1976; Harwood et al., 1976). This inhibition may be only apparent and may reflect a lack of activation of adenylate cyclase in this situation (Saier, 1977; Peterkofsky, 1977). With either mechanism, regulation of adenylate cyclase is thought to involve components of the phosphoenolpyruvate:sugar phosphotransferase system (PTS) (Postma \& Roseman, 1976). Synthesis of adenylate cyclase also appears to be differentially repressed when cells grow with carbon sources causing minimal inhibition of adenylate cyclase activity (Peterkofsky et al., 1975; Pastan \& Adhya, 1976).

Growth of bacteria in a chemostat permits the concentration of limiting metabolites to approach zero in a steady state situation (Herbert et al., 1956). When carbon is limiting, the relevant transport system(s) become less saturated as the flow rate of fresh medium into the chemostat decreases. Consequently the inhibition of adenylate cyclase should be minimized while the putative activation of the enzyme should increase as the cells grow more slowly. Thus it would be expected that accumulation of cyclic AMP in the culture should increase at low dilution rates.

\section{METHODS}

Organism and growth. Salmonella typhimurium 3311 was obtained from B. N. Ames (University of California, Berkeley, U.S.A.). This strain is isogenic with the wild-type strain LT2 except for the $c p d$ (cyclic phosphodiesterase) locus and has less than $2 \%$ of the wild-type cyclic phosphodiesterase activity (EC 3.1.4.17) (Alper \& Ames, 1975). Bacteria were grown at $37^{\circ} \mathrm{C}$ in the phosphate-buffered minimal medium (SMM) described by Alper \& Ames (1975).

Growth in batch culture. Bacteria were grown aerobically to mid-exponential phase in $10 \mathrm{ml}$ SMM plus carbon source $(0.04 \mathrm{M})$ held in $50 \mathrm{ml}$ Erlenmeyer flasks, each fitted with a side-arm and three flutes to increase aeration. Flasks were shaken at $250 \mathrm{rev} . \mathrm{min}^{-1}$. An absorbance of 1.00 at $660 \mathrm{~nm}$ was equivalent to $495 \mu \mathrm{g}$ protein $\mathrm{ml}^{-1}$, protein being measured by the method of Lowry et al. (1951). Bacteria were collected on nitrocellulose filters (previously washed with three changes of boiling distilled water to remove the glycerol used as a plasticizer), washed with 3 to 4 vol. of prewarmed medium and resuspended in 1 vol. of the same medium. For measurements of cyclic AMP synthesis in bacteria growing in the presence of a carbon source, bacteria were washed and resuspended in medium containing the carbon source at $0.04 \mathrm{M}$. Samples were taken at zero time and after $60 \mathrm{~min}$. For measurements of cyclic AMP synthesis in bacteria aerated in the absence of a carbon source, bacteria were washed and resuspended in prewarmed SMM. Samples were taken at zero time and after 5,10 and $20 \mathrm{~min}$; rates of cyclic AMP synthesis were calculated from slopes of least squares fit plots of the data.

Measurements of cyclic AMP synthesis in bacteria aerated in the absence of a carbon source provide a measure of adenylate cyclase activity comparable to that obtained with the adenosine pulse technique (Peterkofsky \& Gazdar, 1973) or by treating bacteria with toluene (Harwood \& Peterkofsky, 1975). The rates of cyclic AMP synthesis obtained are much higher than those measured in vitro with cell extracts (Rephaeli \& Saier, 1976). The rate of cyclic AMP synthesis was linear for at least 20 min regardless of the carbon growth source. 
Analytical techniques. Samples for all cyclic AMP determinations were rapidly collected in an equal volume of boiling sodium acetate buffer $(300 \mathrm{~mm}, \mathrm{pH} 4)$ and boiled for $5 \mathrm{~min}$. Debris was removed by centrifugation. The supernatant was decanted into a second tube, sealed with Parafilm and stored at $-10^{\circ} \mathrm{C}$ until assayed. These samples included both extracellular and intracellular cyclic AMP, which was measured by a modification (Botsford, 1975) of the Gilman assay (1970). Assays were run at least twice in triplicate; mean values are presented.

The concentration of glucose in the growth chamber was determined, after removing the bacteria by filtration, using the Glucostat reagent and the protocol recommended by the supplier (Worthington Biochemicals, Freehold, New Jersey, U.S.A.),

Growth in continuous culture. Bacteria were grown in chemostats described by Koch (1971). The culture volume was $200 \mathrm{ml}$. For both aeration and mixing, growth vessels were continuously sparged with sterile, prewarmed, humidified air at $0.751 \mathrm{~min}^{-1}$. This rate was sufficient to preclude oxygen limitation (Dolezal \& Kapralek, 1976). Chemostats were inoculated with bacteria (washed three times with sterile SMM) from $1 \mathrm{ml}$ of an overnight culture in SMM plus $0.04 \mathrm{M}$-glucose. The inoculum was added as the flow of medium into the growth chamber was started; this was about $4 \mathrm{~h}$ before the maximum volume was reached. Cultures usually reached a steady state after five generations. Dilution rates were calculated from measurements of the volume of medium used and the elapsed time in the experiment. Bacterial numbers were determined by plate counts using nutrient agar medium. For measurements of protein, 5 to $10 \mathrm{ml}$ bacteria were collected by filtration (Gelman, HA-6, $0 \cdot 22 \mu \mathrm{m}$ pore size), resuspended in a smaller volume of water and the protein content was determined by the method of Lowry et al. (1951): 10.4 $\times 10^{9}$ bacteria were equivalent to $1 \cdot 1 \mathrm{mg}$ protein under these conditions.

Samples for cyclic AMP determinations were taken from the growth chamber and treated as for batch cultures.

RESULTS AND DISCUSSION

\section{Cyclic AMP synthesis in batch culture}

In bacteria which had previously been grown with a carbon source, cyclic AMP synthesis was subsequently inhibited by the same carbon source. Suspensions of bacteria previously grown with glucose accumulated cyclic AMP at $2.65 \mathrm{pmol} \mathrm{min}^{-1}(\mathrm{mg} \text { protein })^{-1}$ in the presence of glucose and at $150.6 \mathrm{pmol} \mathrm{min}^{-1}(\mathrm{mg} \text { protein })^{-1}$ in the absence of glucose. Similarly, for bacteria pre-grown with fructose, the rates of cyclic AMP synthesis with and without fructose were 3.96 and 98.4 ; with glycerol, the respective rates were 3.53 and 65.4 ; with ribose, 3.27 and $54 \cdot 5$; and with citrate, 4.50 and $53.9 \mathrm{pmol} \mathrm{min}^{-1}$ (mg protein) ${ }^{-1}$. These results suggest that adenylate cyclase was being repressed (Peterkofsky et al., 1975; Pastan \& Adhya, 1976). Somewhat similar results have been obtained with $E$. coli using toluene lysed cells (Peterkofsky et al., 1975).

To determine the concentration of carbon source required to inhibit cyclic AMP synthesis, bacteria grown with glucose were washed and resuspended in SMM with different concentrations of glucose. Cyclic AMP synthesis, measured after $5 \mathrm{~min}$, was inhibited when the glucose concentration was $50 \mu \mathrm{M}$ or greater (data not presented). Similar results have been obtained with $E$. coli using the adenosine pulse technique to measure adenylate cyclase activity (Peterkofsky \& Gazdar, 1974).

\section{Cyclic AMP synthesis in continuous culture}

In bacteria growing in carbon-limited chemostats, cyclic AMP synthesis decreased with decreasing dilution rate (Fig. 1) regardless of the carbon source and the mechanism by which it was transported into the cells. Glucose and fructose are transported by PTS mechanisms, glycerol is transported by a facilitated diffusion mechanism and ribose is transported by an active transport mechanism independent of the PTS (Postma \& Roseman, 1976).

When bacteria were removed from the chemostat, washed and aerated in the absence of a carbon source, rates of cyclic AMP synthesis were much higher than in those growing in the chemostat (Fig. 2). Measurements of glucose in the growth chamber showed that less than $14 \mu \mathrm{M}$-glucose remained at a dilution rate of $0.4 \mathrm{~h}^{-1}$, and at lower dilution rates, no glucose could be detected. However, extracellular catabolic intermediates can accumulate even under conditions of glucose limitation that provide only $10 \%$ of the bacterial yield obtained in our 


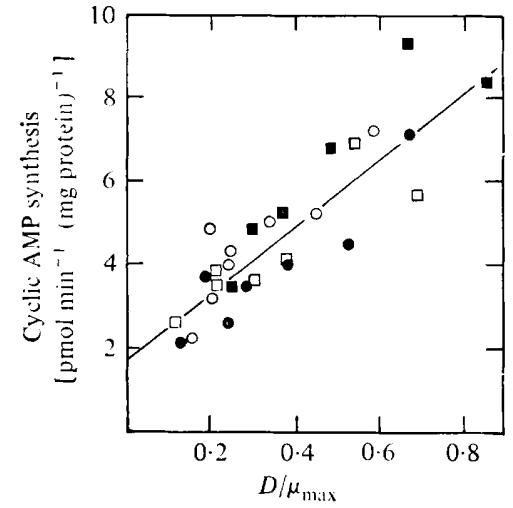

Fig. 1

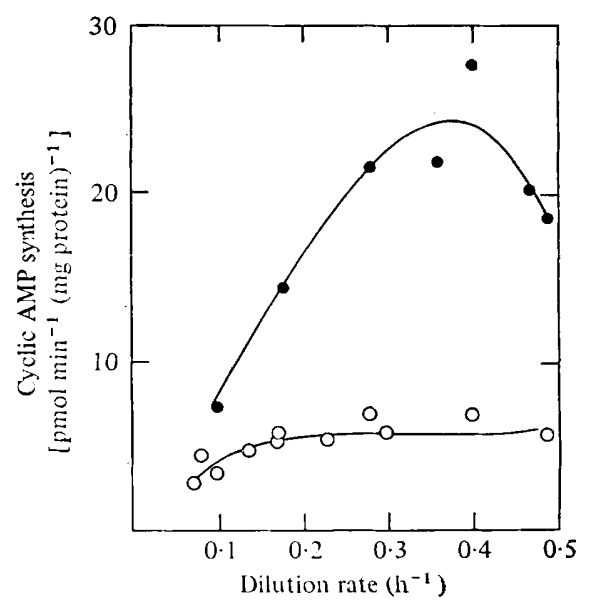

Fig. 2

Fig. 1. Cyclic AMP synthesis as a function of growth rate in continuous culture. Salmonella typhimurium 3311 was grown in carbon-limited chemostats as described in Methods. After seven doublings samples were taken and cyclic AMP accumulation and bacterial protein in the culture were determined. The concentrations of the four carbon sources were chosen (from preliminary experiments) to provide comparable bacterial yields; 170 to $230 \mu \mathrm{g}$ protein $\mathrm{ml}^{-1}$ was afforded by these conditions. In general, lower dilution rates afforded fewer bacteria than high dilution rates. Rates of cyclic AMP synthesis were calculated from the cyclic AMP accumulation measured in the culture and the dilution rate. The rate of cyclic AMP synthesis is plotted as a function of the dilution rate (D) divided by the maximum specific growth rate $\mu_{\max }$ permitted in batch culture; this normalizes the data with respect to the growth rates afforded by the various carbon sources. The line represents a least squares fit of the data and is described by the equation $y=8 \cdot 327 x+1 \cdot 6852$. Carbon sources: $\bigcirc$, glucose; $\bigcirc$, fructose; $\square$, glycerol; $\square$, ribose. Specific growth rates $\left(\mathrm{h}^{-1}\right)$ in batch culture with glucose, fructose, glycerol and ribose as carbon sources were $1 \cdot 35,1 \cdot 55,1 \cdot 60$ and $2 \cdot 00$, respectively. Fig. 2. Cyclic AMP synthesis in bacteria grown in continuous culture at various dilution rates and aerated in the absence of a carbon source. Salmonella typhimurium 3311 was grown as in Fig. 1 with glucose as the carbon source. After seven doublings samples were taken for measurements of bacterial protein and cyclic AMP accumulation. A second sample was taken and bacteria were collected by filtration, washed with 4 vol. of prewarmed SMM and resuspended in an equal volume of SMM. Samples for cyclic AMP determinations were taken at 0,7 and $14 \mathrm{~min}$; rates of cyclic AMP synthesis were calculated from these values. $\bigcirc$, Rates of cyclic AMP synthesis in continuous culture; , rates of cyclic AMP synthesis in bacteria removed from the chemostat, washed, and aerated in the absence of a carbon source. Lines were fitted by inspection.

chemostats (Landwall \& Holme, 1977); such intermediates could be the cause of adenylate cyclase inhibition.

The capacity of the culture to synthesize cyclic AMP in the absence of inhibition reached a maximum at a dilution rate of about $0.4 \mathrm{~h}^{-1}$ (Fig. 2). The reason for this behaviour is not apparent. It may be significant that the concentration of glucose in the growth chamber at this dilution rate was $14 \mu \mathrm{M}$ which is approximately the $K_{s}$ for growth of $E$. coli with limiting glucose (Herbert \& Kornberg, 1976). This concentration is also approximately the $K_{\mathrm{m}}$ for glucose transport (Postma \& Roseman, 1976). Adenylate cyclase activity measured by the adenosine pulse technique in $E$. coli growing in conventional batch culture reached a peak in the early-stationary growth phase and then decreased very rapidly (Peterkofsky \& Gazdar, 1974).

It should be noted that the maximum rate of cyclic AMP synthesis in bacteria grown in glucose-limited chemostats and then aerated in the absence of glucose (Fig. 2) was only about $17 \%$ of that observed in bacteria grown in batch culture with glucose as carbon source.

The results obtained demonstrate that cyclic AMP synthesis in continuous culture is not as would be predicted from studies in batch culture. Synthesis of the nucleotide is influenced by factors other than inhibition or activation of adenylate cyclase consequent to transport of 
carbon sources. The putative activation of adenylate cyclase may be limiting when bacteria grow in carbon-limited chemostats. The proposed activator or perhaps adenylate cyclase per se may be less stable under these conditions. Alternatively, synthesis of adenylate cyclase or some activator protein may be repressed in response to longer generation times, as has been shown for several enzymes in glutamate metabolism (Harvey, 1970), superoxide dismutase (Hassan \& Fridovitch, 1977) and mRNA of the trp operon (Rose \& Yanofsky, 1972).

Much of this investigation was carried out by J. G. Harman in partial fulfilment of the requirements for the M.S. degree from New Mexico State University. The work was supported by funds from NSF Grant BMS 7502249 to J. L. Botsford.

\section{REFERENCES}

AlPer, M. D. \& AMEs, B. A. (1975). Cyclic 3',5'adenosine monophosphate phosphodiesterase of Salmonella typhimurium. Journal of Bacteriology 122, 1081-1086.

BotSFORd, J. L. (1975). Metabolism of cyclic adenosine $3^{\prime}, 5^{\prime}$-monophosphate and induction of tryptophanase in Escherichia coli. Journal of Bacteriology 124, 380-390.

Dolezal, J. \& Kapralek, F. (1976). Physiological characteristics of chemostatically grown Citrobacter freundii as a function of the specific growth rate and nutrient limitation. Folia microbiologica 21, 168-177.

GilmaN, A. G. (1970). A protein binding assay for cAMP. Proceedings of the National Academy of Sciences of the United States of America 67, 305311.

HaRvey, R. J. (1970). Metabolic regulation in glucose limited chemostat cultures of Escherichia coli. Journal of Bacteriology 104, 698-706.

Harwood, J. P. \& Peterkofsky, A. (1975). Glucosensitive adenylate cyclase in toluene treated cells of Escherichia coli. Journal of Biological Chemistry 250, 4656-4667.

Harwood, J. P., Gazdar, C., Prasad, C. Curtis, S. J., Epstein, W. \& Peterkofsky, A. (1976). Involvement of the glucose enzymes II of the sugar phosphotransferase in the regulation of adenylate cyclase in Escherichia coli. Journal of Biological Chemistry 251, 2462-2468.

Hassan, H. M. \& Fridovitch, I. (1977). Physiological function of superoxide dismutase in glucose limited chemostat cultures of Escherichia coli. Journal of Bacteriology 130, 805-811.

Herbert, D. \& Kornberg, H. L. (1976). Glucose transport as rate-limiting step in the growth of Escherichia coli on glucose. Biochemical Journal 156, 477-480.

Herbert, D., Elsworth, R.\& Telling, R. C. (1956). The continuous culture of bacteria: a theoretical and experimental study. Journal of General Microbiology 14, 601-622.

$\mathrm{KoCH}$, A. L. (1971). The adaptive response of Escherichia coli to a feast and famine existence. Advances in Microbial Physiology 5, 24-56.

Landwall, P. \& Holme, T. (1977). Removal of inhibitors of bacterial growth by dialysis culture. Journal of General Microbiology 103, 345352.

Lowry, O. H., Rosebrough, N. J., Farr, A. L. \& RANDALL, R. J. (1951). Protein measurement with
Folin phenol reagent. Journal of Biological Chemistry 193, 265-275.

Pastan, I. \& AdHya, S. (1976). Cyclic adenosine 5'monophosphate in Escherichia coli. Bacteriological Reviews 40, 527-551.

PETERKOFSKY, A. (1977). Regulation of Escherichia coli adenylate cyclase by phosphorylation-dephosphorylation. Trends in Biochemical Sciences 2, 12-14.

Peterkofsky, A. \& Gazdar, C. (1973). Measurements of cAMP synthesis in intact $E$. coli B. Proceedings of the National Academy of Sciences of the United States of America 70, 2149-2152.

Peterkofsky, A. \& Gazdar, C. (1974). Glucose inhibition of adenylate cyclase in intact cells of Escherichia coli B. Proceedings of the National Academy of Sciences of the United States of America 71, 2324-2328.

Peterkofsky, A., Harwood, J. P. \& Gazdar, C. (1975). Inducibility of sugar sensitivity of adenylate cyclase of E. coli B. Journal of Cyclic Nucleotide Research 1, 11-20.

Postma P. W. \& Roseman, S. (1976). The bacterial phosphoenolpyruvate:sugar phosphotransferase system. Biochimica et biophysica acta 457, 213256.

Rephaeli, A. W. \& SaIER, M. H. (1976). Effects of crp mutations on adenosine $3^{\prime}, 5^{\prime}$-monophosphate metabolism in Salmonella typhimurium. Journal of Bacteriology 127, 120-127.

Rose, J. K. \& YANOFSKY, C. Y. (1972). Metabolic regulation of the tryptophan operon of Escherichia coli: repressor-independent regulation of transcription initiation frequency. Journal of Molecular Biology 69, 103-118.

SAIER, M. H. (1977). Bacterial phosphoenolypyruvate:sugar phosphotransferase systems: structural, functional, and evolutionary interrelationships. Bacteriological Reviews 41, 856-871.

SAIER, M. H. \& Feucht, B. U. (1975). Coordinate regulation of adenylate cyclase and carbohydrate permease by the phosphoenolpyruvate:sugar phosphototransferase system in Salmonella typhimurium. Journal of Biological Chemistry 250, 7078-7080.

Saier, M. H., Feucht, B. U. \& Hofstadter, L. H. (1976). Regulation of carbohydrate uptake and adenylate cyclase activity mediated by the enzyme II of the phosphoenolpyruvate:sugar phosphotransferase system in Escherichia coli. Journal of Biological Chemistry 251, 883-892. 